\title{
The impact of ISO 14001 on production management practices: A survey of malaysian wooden furniture manufacturers
}

\begin{abstract}
A study was undertaken to evaluate the deterrents to the adoption of the ISO 14001, environmental management system and also analyze the transformation in production processes that had taken place among the certified companies in the Malaysian wooden furniture industry. The adoption of ISO 14001 environment management system among wooden furniture manufacturers in Malaysia is limited, primarily due to its high implementation cost as well as the low market demand. However, the ISO 14001 certifiedcompanies value the cultural and technical manufacturing factors and hence, are inclined towards employee training for continuous improvement and high-technology application in furniture manufacturing. Further, the certified-companies are also focused on better product design, logistics services and environmental-friendly production processes, which leads to cost-effective manufacturing. Contrary to common belief, the adoption of ISO 14001 environment management system contributes towards cost competitiveness in wooden furniture manufacturing, which may encourage more manufacturers to adopt the system.
\end{abstract}

Keyword: Continuous improvement, Cost-effective, Environment management system, Environmental-friendly, Furniture, Market-demand 